\title{
Mishima, homosexualidad y esteticismo
}

\author{
José Ricardo Chaves
}

En este ensayo se aborda la relación existente entre belleza, homosexualidad y pensamiento esteticista en la obra de Yukio Mishima. La ilustración se da a partir del análisis de tres obras del escritor japonés: Confesiones de una máscara, El color prohibido y El pabellón de oro, lo cual permite contrastar las visiones del mundo europeo y el japonés con respecto al tema de la sexualidad. Se plantean, además, las similitudes existentes en la obra El retrato de Dorian Gray de Oscar Wilde y la novela El color prohibido. Finalmente, se hace una lectura del lugar que ocupa la belleza, desde el punto de vista de los valores estéticos, en la novela El pabellón de oro.

Palabras Clave: Mishima, homosexualidad, estética, belleza, mundo gay japonés.

This essay addresses the relationship between beauty, homosexuality and aesthetic thought in the work of Yukio Mishima. The argument embarks from the analysis of three works by the Japanese author: Confessions of a Mask, The Forbidden Colour and The Gold Pavillion. This allows for contrasting visions of the European and Japanese worlds on the subject of sexuality. It also posits similarities between The Picture of Dorian Gray by Oscar Wilde and the novel The Forbidden Colour. Finally, we undertake a reading of the place of beauty, from the point of view of aesthetic values, in the novel The Golden Pavilion.

KeYwords: Mishima, homosexuality, aesthetics, beauty, Japanese gay culture.

Fecha de recepción: 9 de marzo de 2013

Fecha de aceptación: 11 de junio de 2013 

José Ricardo Chaves

Universidad Nacional Autónoma de México

Instituto de Investigaciones Filológicas

Mishima, homosexualidad y esteticismo

A Átsuko Tanabe, in memoriam

Es muy probable que Yukio Mishima haya sido el escritor japonés más conocido en Occidente durante la segunda mitad del siglo xx, tanto en vida como muerto (se suicidó en 1970, a los 45 años), ya que su deceso escandaloso, con rito suicida samurai por destripamiento y decapitación, ambos con espada, lo tornaron figura mundial más allá de la literatura, para ser pasto del periodismo y de la televisión (después vendrían el cine y el documental). Su ruidosa muerte fue la culminación de un proceso de vida en que el escritor tímido y flacucho se transformó en otro, física e intelectualmente poderoso, imagen que él mismo se encargó de promover en diversos medios. Esto, claro, unido a su propio talento y a su alta productividad, tanto en formas literarias cultas como populares, así como otras formas de expresión artística: teatro, cine, fotografía.

La fama lo había acompañado desde sus inicios literarios con Confesiones de una máscara (de 1949), aunque no necesariamente por las mejores razones, pues la novela narraba en primera persona el despertar y desarrollo de la homosexualidad sadomasoquista de un personaje masculino (supuesto reflejo del autor), quien descubre sus gustos sexuales lo mismo ante un joven limpiador de letrinas, con su carga 
de excrementos, con sus axilas sudorosas (que se volverán su fetiche personal), que ante la reproducción fotográfica del san Sebastián renacentista de Guido Reni, icono cristiano que lo obsesionará tanto, que posteriormente Mishima se hará fotografiar en parecida composición. Hay que recordar que dicho santo ha sido incorporado en la cultura gay como su "patrono", en quien se honra su viril belleza adolorida.

Ya desde esa novela, Mishima establece el tópico literario de la muerte del bello varón, que él remite explícitamente a dos autores emblemáticos del fin de siglo XIX europeo: el irlandés Oscar Wilde y el francés Joris-Karl, Huysmans, verdaderos popes del decadentismo esteticista. En una versión mucho más macabra, Mishima confiesa su debilidad por "la muerte, la noche y la sangre" (Confesiones..., 23): "la escasez de sangre, inherente en mí, me había arraigado el deseo de soñar con derramamientos de sangre" (82). Kochan, su personaje, llega a "confundir la naturaleza de sus deseos sexuales con un sistema estético" (35), según su propia expresión, con lo que muy pronto homosexualidad y estética quedan imbricadas en un culto sangriento a la belleza masculina.

\section{La "belleza negativa"}

Si bien en Confesiones de una máscara Mishima abordó de frente y en forma directa el asunto de la homosexualidad masculina, en versión masoquista, no puede decirse que sea su único tópico, ni que sea un rasgo exclusivo, pues su personaje se relaciona también con mujeres, con lo que otro tópico se establece: el de amar a la mujer sin desearla sexualmente, con lo que se disocia amor y deseo, como ocurrirá en su siguiente novela al abordar de manera profusa la homosexualidad, titulada El color prohibido (de 1951, apenas dos años después), y con la que se supera el intimismo de la narración en primera persona de Confesiones y se pasa a la colectividad de la tercera persona. Si bien hay interiorización en personajes complejos, hay también un cuadro de época sobre el mundo gay japonés de posguerra. Sus personajes homosexuales pueden acostarse con mujeres, a veces lo hacen, pero siguen fieles al amor viril, que conforma su perspectiva interior. Lo suyo no es impotencia física. Tampoco se trata de bisexuales, que desean a los dos 
sexos por igual, pues sólo desean a uno, al masculino, aunque a veces amen al femenino, según afirmen, si bien con una visión misógina.

El culto a la belleza está presente en Mishima, a veces en un nivel alto de abstracción, cuando se hace referencia a la belleza en el arte, la literatura o la naturaleza, pero otras veces se concreta magníficamente en un cuerpo masculino palpable. En su valoración, Mishima retoma a famosos sexólogos del XIX y principios del xx, como Hirschfeld y Havelock Ellis, a quien cita: "Según este autor, sólo los homosexuales son sensibles a la belleza del cuerpo masculino, y hubo que esperar la aparición de un homosexual como Winckelmann - pionero del helenismo moderno- para que se estableciera un sistema de la estética masculina en la escultura griega" (El color prohibido, 120). Los heterosexuales, ya sean hombres o mujeres, casi siempre son insensibles a los misterios más hondos de la belleza viril (hay sus excepciones, como el Shonsuké de Color prohibido), como si sólo el propio sexo fuera capaz de percibir los niveles más íntimos de la belleza. En Confesiones, el personaje creado por Mishima se excitaba sexualmente ante "la estatua de un joven desnudo, plasmada según los criterios clásicos griegos" (99). San Sebastian será su versión cristiana. Su gusto por el arte griego se mantiene, aunque levemente modificado, pues en Color prohibido se describe la primera aparición del hermoso personaje Yuichi, saliendo del mar, en estos términos: "Era un joven de sorprendente belleza. La seducción que se desprendía de su cuerpo era suave, casi dubitativa, y evocaba no tanto una estatua griega de la época clásica como un Apolo esculpido en bronce por un artista de la escuela del Peloponeso" (36).

Más adelante afirma que "de las delicadas líneas de aquel cuerpo irradiaba una fragancia que evocaba la 'dulzura prerrenacentista' a la que se refirió Walter Pater" (37), el famoso esteta del siglo XIX. Hay, pues, en estas novelas de Mishima un vínculo constante entre belleza, homosexualidad y pensamiento esteticista del siglo romántico (Pater, Wilde, Huysmans, lo mismo que Flaubert, Villiers de l'Ile Adam, Byron, Keats, Rodenbach y Beardsley, mencionados explícitamente). El autor había abierto su primera novela, con un epígrafe de Dostoievski que alude a la "belleza de Sodoma” en forma de pregunta: “¿Hay belleza en Sodoma? Creedme, muchos son los hombres que encuentran su belleza en Sodoma. ¿Sabíais este secreto? Lo más horroroso es que la 
belleza no sólo es aterradora, sino también misteriosa. Dios y el Diablo luchan en ella, y su campo de batalla es el corazón del hombre" (Confesiones..., 5).

Vemos que Mishima califica a la belleza de "aterradora" y "misteriosa". En Color prohibido hablará de la "belleza negativa", "la que es imprevista, inquieta, nefasta; la que es desdichada, inmoral, anormal" (17), y que está vinculada con la decadencia, la desilusión y el hastío. En dicha novela es el tipo de belleza que caracteriza la obra literaria de uno de sus dos principales personajes masculinos: Shunsuké, el escritor viejo, feo y heterosexual que manipulará al hermoso y homosexual Yuichi para vengarse de las mujeres. Shunsuké sabe francés, conoce la literatura europea del XIX, ha traducido a Huysmans y a Rodenbach al japonés. Fue romántico en su juventud y después quiso ya no serlo, pero no ha podido romper del todo con "la eternidad romántica". Misántropo y misógino, Shunsuké pacta fáusticamente con Yuichi para que seduzca a hombres y mujeres por él designados, aunque sólo se acueste con aquéllos. Por su parte, el joven Yuichi llega a descubrir su propia belleza gracias a la acción del escritor, igual que le pasó a Dorian Gray bajo el influjo de otro esteta, lord Henry Wotton, sólo que, a diferencia del joven inglés, el japonés sí logrará sobrevivir a su impulsor.

De hecho, es posible pensar en la novela de Mishima como una reelaboración de tópicos de la novela de Wilde, con su mezcla de esteticismo y homosexualidad (algo velada, en la novela de Wilde, aunque activa, como lo muestran algunas de sus adaptaciones cinematográficas: Dallamano 1970, Parker 2009), y abiertamente manifiesta en la de Mishima. Wilde, en su novela, afirma que "A Dorian Gray le había envenado un libro. Había momentos en que consideraba simplemente el mal como un medio necesario para poder realizar su concepción de la belleza" (El retrato de..., 160). A Shonsuké le pasó lo mismo que a Dorian Gray, se envenenó con el libro de Huysmans, pero como era feo, tuvo que usar al bello Yuichi para sus propósitos. Llama la atención que Wilde nunca diga en forma directa que el libro que envenena el alma de Dorian es el de Huysmans, pero para el buen conocedor las señales son claras. De hecho, el capítulo XI de la novela muestra la agenda ética y estética no sólo de Dorian Gray, sino también de Floressas des Esseintes, aunque menos misántropa, pues Dorian no se aleja 
del mundo - todo lo contrario-, a diferencia del célebre personaje de Huysmans. Mishima extiende los atributos negativos de la belleza a la propia homosexualidad que, aunque aceptada por él, es vista con suspicacia, a veces asimilada a la enfermedad y a la fealdad, aunque también, en paradójico giro, a la suprema pureza por conducto de la muerte de los amantes.

En El color prohibido Mishima compara la homosexualidad con "una enfermedad incurable de raíz estética" (82) que vuelve monstruoso e inevitable el apetito carnal, esto en tiempos de modernidad, porque quizá antes, en una edad de oro perdida, el amor viril fue camino de salvación, cruce misterioso de religión, milagro y sexo entre adulto y adolescente, en los tiempos míticos del nanshoku o amor viril de los monjes medievales, que había cedido su lugar a la comercialización y a la prostitución burguesa del periodo Edo, como se aprecia, por ejemplo, en la obra del escritor Ihara Saikaku, del siglo XVII, al que el propio Mishima se refiere (pensaba que desde la obra de Saikaku no se había escrito tan bien sobre la homosexualidad en su país como con su propia novela, Confesiones), igual que hace otras referencias, sin faltar la de Kukai, esto es, Kobo Daishi (774-835), fundador del budismo tántrico en Japón, el Shingon, traído desde China, y a quien se achaca la introducción de la homosexualidad en Japón, venida también de la China, y que quedó asociada así con el budismo. Al respecto apunta Paul Gordon Schalow:

ya para el siglo XVII Kukai se había establecido con firmeza en la iconografía literaria como patrono virtual del amor homosexual; en algunos contextos literarios la sola mención de su nombre o del Monte Koya, lugar donde Kukai fundó el conjunto de los grandes templos del Budismo Shingon, denotaba homosexualidad (El gran espejo..., 16).

\section{La homosexualidad en el contexto japonés}

A diferencia de los escritores europeos del siglo XIX que escribieron pioneramente sobre pasiones homosexuales, y que lo hicieron sobre un trasfondo cultural de vicio, pecado y contranatura, dados los ante- 
cedentes judeocristianos, cuando Mishima lo hace a mediados del xx en Japón, escribe en una tradición literaria en la que la homosexualidad (o sus equivalentes culturales), antes del arribo de la modernidad occidental, no había sido concebida dramáticamente como pecado, sino más bien como una falta relativamente menor, digna a veces más del chiste o de la risa que de castigo y muerte, o bien como paradójico camino de iluminación. Dichas faltas sexuales podían condenarse como transgresiones menores o apegos mundanos, pero su gravedad era menor que las relaciones con mujeres, cuando menos en el ámbito monástico. Los primeros misioneros cristianos en Japón se refirieron al asunto y se escandalizaron, no sólo por la gran difusión de la práctica, sino por la gran tolerancia social al respecto. El nanshoku o amor viril se desarrolló en un ámbito budista, estaba idealmente estructurado sobre la edad (criterio, sin embargo, no siempre existente ni en Saikaku ni en Mishima), pues suponía un adulto y un adolescente, y se daba sobre una base misógina. En su carácter pedagógico y temporal (pues la llegada del adolescente a la adultez marcaba el fin de la relación sexual), se parece mucho, mutatis mutandis, a la paideia griega. Quizá en el contexto monástico tal estilo pederástico de edades diferenciadas fuera dominante, aunque entre más secular el medio, menos fuerte era tal modelo, que podía adquirir formas más igualitarias en edad entre los amantes, sobre todo cuando se privilegia el vínculo entre homosexualidad y amistad. Así, se pregunta Mishima en Color prohibido, novela en la que el criterio de diferencia de edad entre los amantes aparece pero no prevalece:

¿No será que el simple sentimiento de pura amistad que reaparece tras el acto (sexual) es la esencia de la homosexualidad? ¿No está el deseo destinado a producir ese estado de soledad en el que, una vez que ha sido satisfecho, cada uno vuelve a ser un simple individuo del mismo sexo que el otro? Los miembros de esta tribu quieren convencerse de que se aman porque son hombres, pero la realidad es más cruel: ¿no será que al amarse reconocen al fin que son hombres? (401)

El antiguo amor viril japonés encontró fundamentos míticos, según nos señala Bernard Faure, en tres tradiciones: 
one tradition traces the origins of homosexuality as far back as Japanese mythological times, with the legend of the two friends Otake no mikoto and Amano no mikoto. Another mythological tradition goes back to ancient Chinese mythology. A third is purely Buddhist. A compromise between Chinese and Buddhist elements can be found in the legend of King $\mathrm{Mu}$, who received from the Buddha a magical stanza, which he latter transmitted to his young lover to protect him from harm when the latter was sent into exile (The Red Threat, 237).

En la historia japonesa la homosexualidad aparece asociada tanto a los monjes budistas y samurais medievales como a los artistas de después del periodo Kamakura (1185-1333), o los mercaderes del periodo Edo (1603-1868). A diferencia de Occidente, donde las referencias culturales de la homosexualidad son hacia el pecado y el vicio, la herejía o el diabolismo, cuando el cristianismo desplazó al paganismo, en Japón hay instancias culturales de prestigio asociadas con ella: la religión —en especial el budismo-, la milicia, el arte y, menos, el comercio (culpable de la caída del amor viril en la prostitución), aunque esta memoria homosexual se haya a veces atenuado con la modernidad cristiana y secular. Sin duda, como dice Faure, hay una cierta continuidad entre el nanshoku premoderno y la homosexualidad japonesa moderna, que explicaría una imagen relativamente más positiva de ésta, pese a un cierto conservadurismo social.

El discurso tradicional nanshoku proviene de dos periodos diferentes: el tardío medieval o Muromachi (1338-1573) y el premoderno Edo. Literariamente destacan los budistas Cuentos de Chigo, o Chigo Monogatari, en los que se da una idealización de los muchachos, tanto como iniciables a la sexualidad por un adulto amoroso, como iniciadores del adulto en un misterio búdico, como avatares de lo divino. Pareciera que la homosexualidad budista en Japón oscila entre una eufemización (efebización) de la explotación sexual, quizá una sublimada autojustificación de los monjes para acceder al cuerpo adolescente, por una parte, y por otra como la glorificación de la relación pederástica en tanto forma elevada de educación y, a veces, de iluminación, como medio hábil de una deidad budista que asume la forma juvenil deseada por el monje para literalmente ser seducido y llevado a la salvación. Dos conoci- 
dos bodisatvas (esto es, budas que se niegan a asumir su nirvana para beneficiar al resto de los seres sensibles) que adoptan tales métodos transexuales para cumplir sus cometidos iluminadores son Manjushri (Monju), figura de sabiduría con apariencia juvenil, y Kannon, diosa de compasión que, en sus previas versiones en la India y el Tíbet, había sido concebida en forma masculina como Avalokiteshvara y Chenrezig, pero que ya en China cambió de sexo para ser Kuan Yin y Kannon en Japón. ${ }^{1}$

Mishima conoce bien toda esta literatura tradicional y premoderna de nanshoku de su natal Japón, pues en diversas ocasiones se refiere a ella a partir de sus personajes, sobre todo en El color prohibido, aunque, como moderno y secular que es, no cree mucho en los elementos espirituales asociados que estarían en la base mítica de la homosexualidad monástica, tal como se desprende de la ironía usada por su personaje Shonsuké cuando se refiere al chigo como "camino de salvación". De hecho, aunque Mishima aborde asuntos religiosos, cuando lo hace le interesa en tanto fenómeno cultural, histórico o narrativo, no le interesa mucho el aspecto propiamente religioso. Por ejemplo, se vale de la hipótesis budista de la reencarnación en su tetralogía El mar de la fertilidad, pero no como un asunto místico, sino como una estrategia narrativa que le permite desarrollar cierto esquema dramático de un mismo amor con cuatro combinaciones: un miembro envejece a lo largo de las

\footnotetext{
${ }^{1}$ Estos bodisatvas seductores actúan de manera muy distinta a la del Buda histórico ante la admiración de su seguidor Vakkali, un monje que se había convertido, fascinado por la bella apariencia de Buda y que lo seguía embobadamente. En principio, si el mito es cierto, y el cuerpo de Sidarta tenía las 32 marcas físicas de perfección, su belleza debió ser grande, lo que explicaría la actitud de Vakkali y otros (no obstante, algún artista devoto que se puso a dibujar un buda con tales 32 marcas lo que obtuvo fue un monstruo: orejas largas cuyo lóbulo llega a la base del cuello, protuberancia en la coronilla, lengua tan larga que puede tocar cada una de sus orejas, ruedas tatuadas en las plantas de los pies, etc.). A diferencia de los bodisatvas casquivanos, Buda intentó desanimar a su admirador en su obsesión por la apariencia física, por la belleza, cuando pronuncia la sentencia de que "Quien ve el Dharma me ve; quien me ve ve el Dharma". Falló en su empeño y tuvo que pedirle que se alejara. Años después Vakkali buscará reencontrase con Buda, y en el camino enferma, y es tal el dolor de su afección, que se suicida algo aparatosamente cortándose el cuello. Tras su muerte, Buda verá su cuerpo y dirá que obtuvo el nirvana, lo que llevó a algunos a pensar que el suicidio no era incompatible con la iluminación, en casos extremos, como una enfermedad mortal y dolorosa, como fue el caso de Vakkali, enamorado, como Mishima, de la belleza masculina.
} 
cuatro novelas y el otro muere y renace, muere y renace: es el mismo/la misma y es otro y otra.

La visión larga que tiene Mishima de la homosexualidad en Japón se combina con su conocimiento de la homosexualidad en Europa, desde sus antecedentes griegos, por lo que en Color prohibido no faltan las menciones a los textos platónicos (Fedro y El banquete), que se proyectan en el Renacimiento y en el esteticismo romántico del XIX, tan caros al autor japonés.

\section{La belleza vacía}

En una siguiente novela de mediados de la década de 1950, titulada $E l$ pabellón de oro (1956), Mishima retoma el asunto de la belleza en un nuevo contexto. Vuelve a la narración en primera persona de Confesiones pero deja de lado el asunto de la homosexualidad y se concentra en la belleza de un cuerpo no humano, en este caso, un antiguo pabellón budista que captura la imaginación enfermiza del monje narrador, quien pretende alcanzar con sus ojos "la esencia misma de lo Bello", puesto que "no creía en otra belleza que la perceptible por el ojo humano" (27).

El narrador confiesa que "cuando se concentra el espíritu sobre la Belleza, uno cae sin darse cuenta sobre lo más negro que hay en el mundo en materia de ideas tenebrosas" (48). Paulatinamente se establece una especie de duelo entre el monje tartamudo y, más que feo, anónimo, invisible de tan corriente, y el hermoso y antiguo pabellón, en cuya construcción la sangre y la guerra no han sido extrañas:

Nada más natural que guerras y alarmas, montones de cadáveres y ríos de sangre fuesen para la belleza del Templo de Oro una nueva fuente de riqueza. Su propia arquitectura, ¿no era hija del pánico? ¿No había sido concebido y edificado por una muchedumbre de posesos de alma sombría? (37).

La mayoría de las acciones narrativas transcurren en este ambiente monacal budista, en el que los supuestos rigores de tal tipo de vida zen están más bien ausentes, pues los monjes, desde el prior más elevado 
hasta los más jóvenes, se dan sus escapadas para acostarse con jóvenes ingenuas o prostitutas, o beben sake en sus recintos privados, o prestan dinero con intereses. Se confirma la mirada secular de Mishima cuando aborda temas o ambientes religiosos. Progresivamente el hermoso pabellón va adquiriendo una existencia semieterna, se convierte en un símbolo de la desaparición del mundo fenomenal o samsárico, en una maligna influencia que afecta al monje, al grado que la única manera que encuentra para escapar de su hechizo es incendiándolo.

En esta novela, el artista debe destruir la obra de arte para no ser destruido por ella, como un exitoso Dorian Gray que sobreviviera a la destrucción de su retrato para recuperar su vida, su alma empeñada. Es lo opuesto de lo que acontecía en Color prohibido, en que el hermoso Yuichi, marioneta estética del escritor feo, al final se rebela contra su creador, el escritor Shonsuké, empujándolo al suicidio. Aquí, la belleza destruye al artista viejo, mientras que en El pabellón de oro el artista destruye a la belleza para sobrevivir. De esta manera, la pretensión esteticista de otorgar a la belleza el lugar máximo y decisivo es superada. No en balde no queda en esta novela ninguna referencia a la belleza decadente del siglo XIX, concentrándose más bien en las referencias japonesas.

Para disolver la fuerza todopoderosa que la belleza ejerce sobre el artista, Mishima retoma del budismo Zen su enseñanza del vacío como consustancial a la forma, y la forma como consustancial al vacío. Descubre que "el poder de la auténtica visión reside, en suma, en la conciencia de que nuestro corazón no tiene forma ni apariencia. Pero para estar en condiciones de alcanzar esta ausencia de apariencias, ¿no se precisa dirigir a la fascinación de las formas una mirada particularmente aguda?" (124). Y justo es lo que hace el monje al destruir el templo, al comprender que éste no "era sino estructuras minuciosamente elaboradas, edificadas sobre el no-ser", que "estaba saturado de noche", y que "su sustancia estaba hecha de pesadas, suntuosas tinieblas" (145), en una suerte de oscura iluminación.

De tal forma, en esta novela Mishima rompe el contrato esteticista decimonónico que tanto admirara y que otorgaba a la belleza un poder de ídolo, y la reduce a cenizas por el poder del fuego crítico. Quizá sin proponérselo, de manera indirecta, aquí Mishima funciona como un 
buda fallido, pues si bien su personaje logra cierta sabiduría del vacío (prajna), no alcanza sin embargo a desarrollar la otra ala necesaria para volar como bodisatva, que es la compasión (karuna): en palabras de su personaje "carecía del sentido de la expansión y de la solidaridad con todo lo vivo", mismo que lo arrojaba a una soledad que lo perseguía a todas partes sin cesar, concluyendo que "ni siquiera se sentía solidario con la nada" (El pabellón..., 125). Su personaje no sólo obtiene esta paradójica sabiduría oscura, sino que, además, cree que, ya que el sufrimiento es inextirpable en la vida, lo mejor es multiplicarlo en los demás para no sentir tanto el propio, con lo que adquiere así rasgos sádicos, quizá propios de un demonio de algún infierno budista.

\section{REFERENCIAS}

FAure, Bernard, The Red Threat. Buddhist Approaches to Sexuality, New Jersey, Princeton University Press, 1998.

Mishima, Yukio, Confesiones de una máscara, trad. A. Bosch, Barcelona, Planeta, 1987.

Mishima, Yukio, El color prohibido, trad. Keiko Takahashi y Jordi Fibla, Madrid, Alianza Editorial, 2009.

Mishima, Yukio, El pabellón de oro, trad. Juan Marsé, Barcelona, Seix Barral, 1985.

SAIKAKU, Ihara, Historias de amor entre samurais, trad. del inglés de Armand de Fluviá, México, Fontamara, 1984.

SchAlOw, Paul Gordon, "Introducción", en El gran espejo del amor entre hombres, Ihara Saikaku, trad. Amalia Sato, (s.1.), Buenos Aires, Interzona, 2003.

Schalow, Paul Gordon, "The Legend of Kukai and the Tradition of Male Love in Japanese Buddhism" y "Spiritual Dimensions of Male Beauty in Japanese Buddhism", en Queer Dharma, Winston Leyland (ed.), San Francisco, Gay Sunshine Press, 1998.

WiLde, Oscar, El retrato de Dorian Gray, Barcelona, Ramón Sopena, 1959. 